Review Article

\title{
COM PARATIVE EVALUATION OF DIABETOGENIC AND MUTAGENIC POTENTIAL OF ARTIFICIAL SWEETENERS - ASPARTAME, ACESULFAME-K AND SUCRALOSE
}

\author{
Shastry C.S. ${ }^{1}$, Yatheesh C.K. ${ }^{1}$, Aswathanarayana B.J. ${ }^{1}$ \\ ${ }^{1}$ Department of Pharmacology, N.G.S.M . Institute of Pharmaceutical Sciences, Paneer, Deralakatte, \\ Mangalore, Karnataka - 575 018. India \\ Correspondence: \\ Shastry C.S. \\ Department of Pharmacology, NGSM Institute of Pharmaceutical Sciences, Deralakatte, Mangalore - 575 018, Karnataka, India \\ M obile : +919731241373 E-mail : drcshastry@gmail.com
}

\begin{abstract}
:
Objectives: Artificial sweeteners provide the sweetness of sugar without calories. Since from discovery, safety of artificial sweeteners has been controversial as they directly or indirectly link to induce carcinogenic and genotoxic risks. Hence the present study was undertaken to compare the diabetogenic and mutagenic potential of most widely using artificial sweeteners; aspartame, acesulfame-K, and sucralose.

Methods: Diabetic potential is assessed by ascending repeated dose study in which acceptable daily intake (ADI) dose of artificial sweeteners after converting human dose to animal dose using a standard reference table and administered up to 13 weeks with 3 different phases in an ascending manner on experimental rats. Mutagenic potential was accessed by Ames test with and without metabolic activation using Salmonella typhimurium strains TA 97 and TA1535.

Results: At ADI doses between 0-3 weeks, no significant changes but after 13 weeks significant increase was observed in the levels of fasting blood glucose, glycated haemoglobin, total cholesterol, triglyceride, LDL and VLDL in all artificial sweetener groups. Sucralose showed comparatively less increase which was supported by histology reports. In Ames mutagenic assay aspartame, acesulfame-K and sucralose gave negative results.

Conclusion: Aspartame, acesulfame-K and sucralose were found to exhibit diabetogenic effect at higher dose levels but they were safer to use at ADI doses and non mutagenic compounds. Comparatively sucralose is safer than aspartame and acesulfame-K. Hence these artificial sweeteners should be used with caution and over usage is not appreciated.
\end{abstract}

Keywords : Artificial sweeteners, aspartame, acesulfame-K, sucralose, diabetogenic, mutagenic.

\section{Introduction :}

Artificial sweeteners include substances from several different chemical classes that interact with taste receptors and typically exceed the sweetness of sucrose by a factor of 30 to 13,000 times but have no or low calories. They provide only sweetness but not the daily calorie needs [1]. Due to their intense sweetness they are needed in small

\begin{tabular}{|c|}
\hline Access this article online \\
\hline Quick Response Code \\
\hline
\end{tabular}
quantity and hence are economical. Currently FDA approved artificial s we eteners for consumption are acesulfame-K, aspartame, neotame, saccharin, and sucralose, out of which most extensively used sweeteners are aspartame, sucralose and acesulfame- $K$ [2]. As the artificial sweeteners provide the sweetness of sugar without calories, public health attention has turned to reversing the obesity epidemics in the individuals of all ages by choosing to use the products containing artificial sweeteners. Hence the use of low-calorie, sugar-free products tripled in the last two decades of the 20th century. In the United States alone, more than 150 million people use these products regularly. However safety of these artificial sweeteners is unresolved and controversial.

Diabetes mellitus has now assumed epidemic proportions in many countries of the world. With the present population of 19.4 million diabetics, and approximately 60 
million by the year 2025, India would rank first in its share of the global burden of diabetes. When a portion of the population suffers from a disease in which sucrose is the initiating culprit, the treatment choices are to either eliminate the source of glucose or add/regulate the amount of insulin available to the bloodstream [3]. So, in lieu of ridding the diet of sweet, science went looking for a sweet replacement by the artificial sweeteners. But, however recent epidemiologic studies showed the association between diet soda consumption (which contains artificial sweeteners) and the risk of development of obesity, metabolic syndrome and Type 2 diabetes [4,5]. The earlier studies linked artificial sweeteners to carcinogenic and genotoxic risk. Aspartame exhibited carcinogenicity on prolonged use, sucralose in mouse lymphoma assay showed positive mutation frequency at higher doses and acesulfame-K caused slight chromosomal aberration indicating that these artificial sweeteners not entirely safe even though they are FDA approved [6-9].

Aspartame, acesulfame-K and sucralose are not entirely safe as they were artificially synthesized and their metabolites may yield to toxic chemicals. Most importantly, the risk-benefit ratio of artificial sweeteners is unclear. Recent study also shows health risk even below the acceptable daily intake (ADI) doses after the long term consumption. So, further studies are essential to assess the safety of these three artificial sweeteners. Hence present study was undertaken to access the diabetogenic and mutagenic potentials of the artificial sweetenersaspartame, acesulfame-K and sucralose.

\section{Materialsand Methods:}

\section{Chemicals}

Aspartame, acesulfame-K and sucralose were procured by Highmedia Bombay, India. HbA1C (glycated haemoglobin) kit, total cholesterol kit, triglyceride kit, etc, were procured from Agappe diagnostics Ltd, Kerala. And all other chemicals were of analytical grade and used as received.

\section{Animals}

All the experiments were carried out with Sprague-Dawley rats weighing 150-200g. Animals were kept in the animal house of NGSM Institute of Pharmaceutical Sciences, Mangalore under controlled conditions of temperature $\left(23+2{ }^{\circ} \mathrm{C}\right)$, humidity $(50 \pm 5 \%)$ and $12 \mathrm{~h}$ light-dark cycle. Animals were fed pellet diet (Venkateshwara enterprises, Bangalore) and water ad libitum. All the animals were acclimatized for seven days before the study. The experimental protocol was approved by institutional animal ethical committee (approval number: Reg.No.KSHEM A/AEC/39/2010)

\section{Selection of Drug Doses}

The human ADI of aspartame, sucralose and acesulfame- $K$ was $50 \mathrm{mg} / \mathrm{kg}, 15 \mathrm{mg} / \mathrm{kg}$ and $15 \mathrm{mg} / \mathrm{kg}$ respectively. The $\mathrm{ADI}$ doses were converted to animal doses as per the conversion chart and used for the study [10].

\section{Assessment of diabetogenic potential [11,12] Experimental design:}

Diabetic potential accessed by ascending repeated dose study up to 13 week in 3 phases on rats. Study involved 4 groups with 6 animals each. Drugs were administered orally through oral gavage.

" Controlgroup

"Aspartame treated group

"Acesulfame-Ktreated group

"Sucralose treated group

\section{Phase ?(0-3 weeks-ADI dose):}

- Control group: administered with distilled water for 0 3 weeks.

- Aspartame treated group: administered with 315 $\mathrm{mg} / \mathrm{kg}$ rat

- Acesulfame-K treated group: administered with 94.5 $\mathrm{mg} / \mathrm{kg}$ rat

- Sucralose treated group: administered with 94.5 $\mathrm{mg} / \mathrm{kg}$ rat

\section{Phase II (3-7 weeks- 2 xADI dose):}

- Control group: administered with distilled water

- Aspartame treated group: administered with 630 $\mathrm{mg} / \mathrm{kg}$ rat

- Acesulfame-K treated group: administered with 75.6 
$\mathrm{mg} / \mathrm{kg}$ rat

- Sucralose treated group: administered with 75.6 $\mathrm{mg} / \mathrm{kg}$ rat

\section{Phase III (7-13 weeks- 4 xADI dose):}

- Control group: administered with distilled water

- Aspartame treated group: administered with 1260 $\mathrm{mg} / \mathrm{kg}$ rat

- Acesulfame-K treated group: administered with 151.2 $\mathrm{mg} / \mathrm{kg}$ rat

- Sucralose treated group: administered with 151.2 $\mathrm{mg} / \mathrm{kg}$ rat

At the end of 3rd, 7th, 13th week rats were fasted for 18 hour and the fasting blood glucose (FBG) levels were measured. Blood was collected by retro orbital sinus method [13] and centrifuged at $2500 \mathrm{rpm}$. Serum was separated and lipid profiles like total cholesterol, triglyceride, LDL and VLDL was measured along with the $\mathrm{HbA1C}$ levels which are measured only at the end of the 13th week.

\section{Assessment of mutagenic potential by Ames test $[14,15]$}

For comparative evaluation of mutagenic potential, samples of aspartame, acesulfame-K, and sucralose were sent to Shree Dhanwantary Pharmaceutical Analysis and Research Centre (SDPARC) at Kim, Surat, Gujrat. The potential of mutagenic effects of aspartame, acesulfame-k and sucralose were evaluated on two Salmonella typhimurium strains TA97 (Detects frame shift mutations) and TA1535. (Detects base pair substitution mutations). with and without metabolic activation. Salmonella/ microsome reversion assay was conducted using the plate incorporation procedure described by Maron and Ames and as per 471-OECD guidelines for testing of chemicals.

\section{Statistical Analysis :}

The data were expressed as mean \pm standard error of the mean (S.E.M .) of 6 animals per group. Parametric one way analysis of variance (ANOVA) followed by Dunnett's test. Statistical analysis was performed using Graph pad prism 5.0. The minimal level of significance was identified at $\mathrm{P} \varangle 0.05$.

\section{Results:}

\section{Assessment of a diabetogenic potential}

\section{Fasting blood glucose level}

In Phase I, at ADI doses of aspartame, acesulfame-K and sucralose, FBG level were found to be similar/slightly lower than control group values in all the drug treated groups. In Phase II (at 2 XADI doses) and phase III (at 4 XADI doses) of aspartame, acesulfame-K and sucralose, the FBG level was significantly raised ( $p \varangle 0.001$ ) in all the drug treated groups compared control group indicating induction of diabetes. In comparison with aspartame and acesulfame-K, sucralose shows less increase in FBG levels. (Table 1)

\section{HbAlc Leve}

After the 13 week, HbAlC levels were raised significantly $(p<0.001)$ in all three drug treated groups (aspartame, acesulfame-K and sucralose) compared to control group. However the sucralose shows less increase compared to other two artificial sweetener groups. (Table 2)

\section{Lipid profile}

In Phase I, lipid profiles like Total cholesterol, Triglyceride level, LDL and VLDL levels were normal as control group. But at phase II and phase III there was significant $(p<0.001)$ increase in lipid profile of all artificial sweetener treated groups compared to control group. (Table 3)

\section{Assessment of mutagenic potential by Ames test}

Ames test with and without metabolic activation results revealed Aspartame, Acesulfame-K and Sucralose were non mutagenic.

\section{Histology}

Histology of normal rat pancreas showed no architectural changes. Aspartame treated rat pancreas showed diffused necrotic changes. Acesulfame-K treated rat pancreas showed focal lymphocytic aggregation/focal chronic infiltrate in the form of lymphocyte indicating autoimmune response against $\beta$ cells. Histology of sucralose treated rat pancreas showed no significant architectural changes which is comparable with normal rat pancreas. (Figure 1) 
Table 1: Effect of aspartame, acesulfame-K and sucralose on FBG level

\begin{tabular}{|l|l|l|l|}
\hline Group & \multicolumn{3}{|l|}{ Fasting Glucose Level $\mathbf{( m g / d \mathbf { ~ } )}$} \\
\hline & $\mathbf{0 - 3}$ weeks & $\mathbf{3 - 7}$ weeks & $\mathbf{7 - 1 3}$ weeks \\
\hline Control group & $73.00 \pm 1.78$ & $78.21 \pm 4.18$ & $78.33 \pm 1.96$ \\
\hline Aspartame treated & $73.17 \pm 2.13$ & $86.24 \pm 5.45^{\mathrm{a}}$ & $120.50 \pm 1.37^{\mathrm{a}}$ \\
\hline Acesulfame-K treated & $72.67 \pm 1.03$ & $93.20 \pm 5.65^{\mathrm{a}}$ & $124.00 \pm 3.03^{\mathrm{a}}$ \\
\hline Sucralose treated & $73.83 \pm 1.72$ & $87.69 \pm 5.60^{\mathrm{a}}$ & $118.80 \pm 3.37^{\mathrm{a}}$ \\
\hline
\end{tabular}

The Values are expressed as M ean $\pm \mathrm{SEM}, \mathrm{n}=6$ rats in one group. ${ }^{\text {a }}$ significant compared with control group $(p<0.001)$.
Table 2: Effect of Aspartame, Acesulfame-K and Sucralose on HbAlc level

\begin{tabular}{|l|l|}
\hline Group & HbAlc level (\%) \\
\hline Control group & $5.83 \pm 0.73$ \\
\hline Aspartame treated & $7.05 \pm 0.26^{\mathrm{a}}$ \\
\hline Acesulfame-K treated & $6.68 \pm 0.02^{\mathrm{a}}$ \\
\hline Sucralose treated & $6.52 \pm 0.08^{\mathrm{a}}$ \\
\hline
\end{tabular}

The Values are expressed as Mean \pm SEM , $n=0$ rats in one group. ${ }^{a}$ significant compared with control group $(p \varangle 0.001)$

Table 3: Effect of aspartame, acesulfame-K and sucralose on Lipid profiles

\begin{tabular}{|l|l|l|l|l|l|l|}
\hline \multirow{2}{*}{ Group } & \multicolumn{3}{|c|}{ Total cholesterol (mg/dl) } & \multicolumn{3}{c|}{ Triglyceride level (mg/dl) } \\
\cline { 2 - 7 } & $0-3$ weeks & $3-7$ weeks & $7-13$ weeks & $0-3$ weeks & $3-7$ weeks & $7-13$ weeks \\
\hline Control group & $67.50 \pm 2.07$ & $68.67 \pm 2.16$ & $71.67 \pm 4.63$ & $67.83 \pm 4.83$ & $72.00 \pm 2.00$ & $74.17 \pm 2.56$ \\
\hline Aspartame treated & $69.50 \pm 4.23$ & $81.50 \pm 3.39^{\mathrm{a}}$ & $82.50 \pm 2.66^{\mathrm{a}}$ & $72.50 \pm 2.66$ & $78.00 \pm 2.19^{\mathrm{a}}$ & $90.17 \pm 6.49^{\mathrm{a}}$ \\
\hline Acesulfame-K treated & $68.83 \pm 2.85$ & $76.83 \pm 1.47^{\mathrm{a}}$ & $84.50 \pm 2.34^{\mathrm{a}}$ & $71.33 \pm 1.50$ & $77.67 \pm 1.50^{\mathrm{a}}$ & $95.67 \pm 11.60^{\mathrm{a}}$ \\
\hline Sucralose treated & $69.17 \pm 3.31$ & $74.00 \pm 2.36^{\mathrm{a}}$ & $81.67 \pm 1.36^{\mathrm{a}}$ & $71.67 \pm 3.55$ & $77.50 \pm 2.42^{\mathrm{a}}$ & $87.83 \pm 6.49^{\mathrm{a}}$ \\
\hline
\end{tabular}

\begin{tabular}{|l|l|l|l|l|l|l|}
\hline \multirow{2}{*}{ Group } & \multicolumn{3}{|c|}{ LDL cholesterol (mg/dl) } & \multicolumn{3}{c|}{ VLDL-C (mg/dl) } \\
\cline { 2 - 7 } & $0-3$ weeks & $3-7$ weeks & $7-13$ weeks & $0-3$ weeks & $3-7$ weeks & $7-13$ weeks \\
\hline Control group & $17.27 \pm 3.13$ & $18.93 \pm 3.74$ & $20.82 \pm 3.27$ & $13.57 \pm 0.96$ & $14.40 \pm 0.40$ & $14.83 \pm 0.51$ \\
\hline Aspartame treated & $20.42 \pm 2.00$ & $32.97 \pm 2.50^{\mathrm{a}}$ & $32.64 \pm 6.98^{\mathrm{a}}$ & $14.08 \pm 0.90$ & $15.51 \pm 0.43^{\mathrm{a}}$ & $18.03 \pm 1.29^{\mathrm{a}}$ \\
\hline Acesulfame-K treated & $20.73 \pm 3.25$ & $31.13 \pm 2.59^{\mathrm{a}}$ & $40.80 \pm 7.25^{\mathrm{a}}$ & $14.27 \pm 0.30$ & $15.53 \pm 0.30^{\mathrm{a}}$ & $19.13 \pm 2.32^{\mathrm{a}}$ \\
\hline Sucralose treated & $21.07 \pm 4.63$ & $27.67 \pm 5.59^{\mathrm{a}}$ & $35.03 \pm 1.95^{\mathrm{a}}$ & $14.33 \pm 0.711$ & $15.50 \pm 0.48^{\mathrm{a}}$ & $17.77 \pm 1.09^{\mathrm{a}}$ \\
\hline
\end{tabular}

The Values are expressed as M ean \pm SEM , $n=6$ rats in one group. ${ }^{a}$ significant compared with control group $(p<0.001)$.

\section{Discussion :}

In the present diabetogenic study, ascending repeated dose 13 weeks with three phases gave the clear indication of effect of these artificial sweeteners at various dose levels. The doses started at ADI doses since recent long term studies indicated aspartame not safe even at daily acceptable doses [7]. M utagenic potential was accessed by Ames test with and without metabolic activation using Salmonella typhimurium strains TA 97 and TA1535.

Present study revealed that the artificial sweeteners cause significant increase in FBG levels, $\mathrm{HbA1C}$ levels and lipid profile. The sucralose group showed lesser increase compared to other two artificial sweeteners. The pancreatic histology report supports the same. The Ames test was negative for all three artificial sweeteners.

\section{Conclusion :}

From the present study it was confirmed that aspartame, acesulfame-K and sucralose exhibit diabetogenic effect at higher dose levels but they were safer to use at ADI doses.
They were non mutagenic compounds, confirmed from the Ames mutagenic test with and without metabolic activation. So study indicated these artificial sweeteners can be used with caution to limited extent. Over usage above the ADI doses and long term usage of these artificial sweeteners is not advisable.

Overall comparative evaluation showed that sucralose found to be safer than aspartame and acesulfame-K. The study also appreciates the carrying a similar long term study for these sweeteners for further safety assessment on health risks.

\section{Acknowledgements:}

The authors are grateful to Nitte Education Trust, Nitte University and Department of Pharmacology, NGSM Institute of Pharmaceutical Sciences, Deralakatte, Paneer, $M$ angalore for providing the necessary facility and their full co-operation to carry out the research work. 


\section{Conflict of interest}

The authors declare that they have no conflicts of interest to disclose.

Figure 1 : Histology report

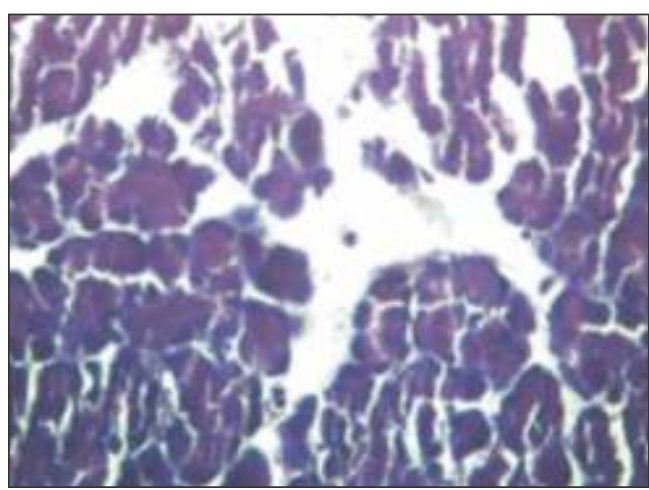

Control group

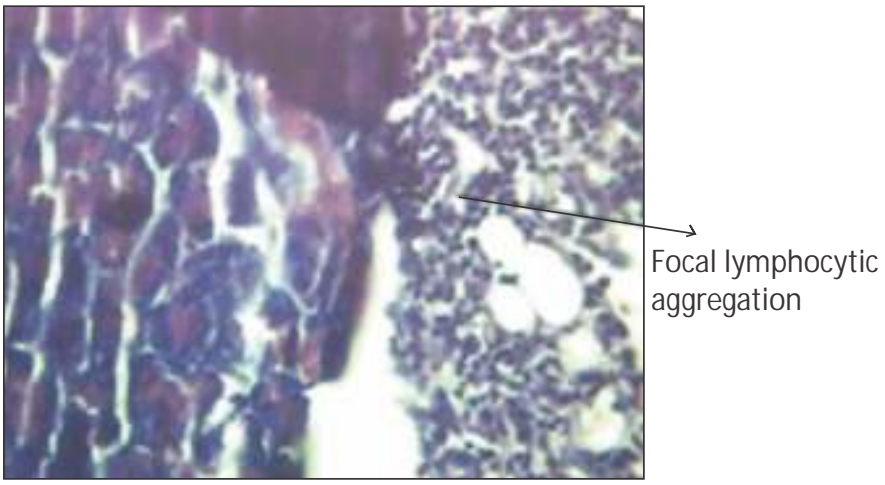

Acesulfame-K treated group

\section{Funding:}

This study received no specific grant from any funding agency in the public, commercial or not for profit sectors.

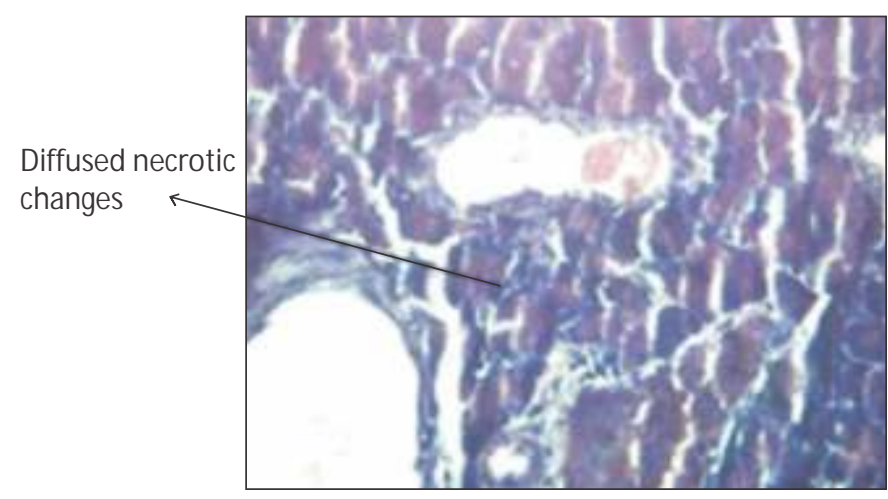

Aspartame treated group

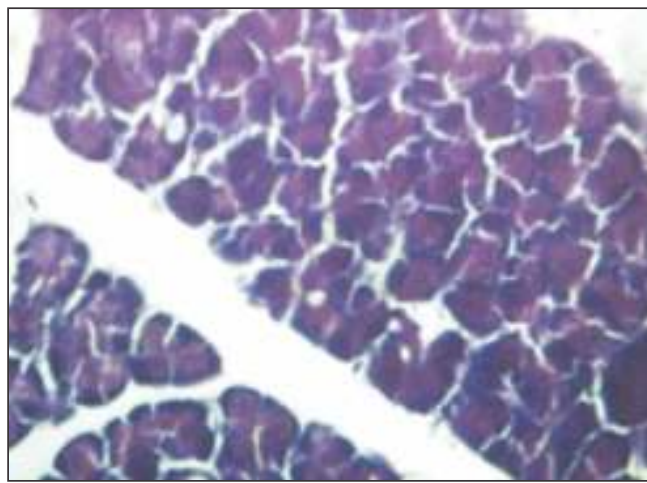

Sucralose treated group

\section{References}

1. Erina EVH. Artificial Sweeteners: their origin and mechanism. Cited on 2009. Available from: URL:www.clfs.umd.edu/grad/mlfsc/ Artificial\%20Sweeteners.pdf

2. Duffy VB, Grant SM . Position of the american dietetic association: use of nutritive and nonnutritive sweeteners. J Am Diet Assoc 2004;104(2):255-75.

3. Tripathi BK, Srivastava AK. Diabetes mellitus: complications and therapeutics. M ed Sci M onit 2006;12(7):130-47.

4. Nettleton JA, Lutsey PL, Wang Y, Lima JA, M ichos ED, Jacobs DR. Diet soda intake and risk of incident metabolic syndrome and type 2 diabetes in the multi-ethnic study of atherosclerosis (M ESA). Diabetes Care 2009;32(4):688-9.

5. Fowler SP, Williams K, Resendez RG, Hunt KJ, Hazuda HP, Stern MP. Fueling the obesity epidemic? artificially sweetened beverage use and long-term weight gain. Obesity 2008;16(8):1894.

6. Soffritti M, Belpoggi F, Esposti DD, Lambertini L, Tibaldi E, Rigano A. First experimental demonstration of the multipotential carcinogenic effects of aspartame administered in the feed to sprague-dawley rats. Environ Health Perspect 2006;114:379-85.

7. Soffritti M, Belpoggi F, Esposti DD, Tibaldi E, Lauriola M . 2007. Life-span exposure to low doses of aspartame beginning during prenatal life increases cancer effects in rats. Environ Health Perspect 2007;115:1293-97.
8. Bandyopadhyay A, Ghoshal S, Mukherjee A. Genotoxicity Testing of low- calorie sweeteners: aspartame, acesulfame-k, and saccharin. Drug Chem Toxicol 2008;31(4):447-57

9. Mukherjee A, Chakrabarti J. In vivo cytogenetic studies on mice exposed to acesulfame-K-a non-nutritive sweetener. Food Chem Toxicol 1997;35(12):1177-9.

10. Ghosh MN. Fundamentals of experimental pharmacology. 4th ed. Kolkata; Hilton and company: 2008. pp: 178.

11. Nafisa PCF, Chakradha VL, Vandana SP, Suresh RN. An experimental evaluation of the antidiabetic and antilipidemic properties of standardized Memodica charantia fruit extract. BMC Complemen Alter M ed 2007;7(29):1-8.

12. M cLean BI, Shephard NW, M errit RJ, Hildick-Smith G. Repeated dose study of sucralose tolerance in human subjects. Food Chem Toxicol 2000;38(2):123-9

13. Kakadiya J, Shah M, Shah NJ. Effect of nobivolol on serum diabetic marker and lipid profile in normal and streptozotocin-nicotinamide induced diabetic rats. Biol Chem Sci 2010;1:329-334.

14. Mortelmans $K$, Zeiger $E$. The ames salmonella/microsome mutagenicityassay. M utat Res 2009;455(1-2):29-60.

15. Maron DM, Ames BN. Revised methods for the salmonella mutagenicity test. Mutat Res 1983;113:173-215. 